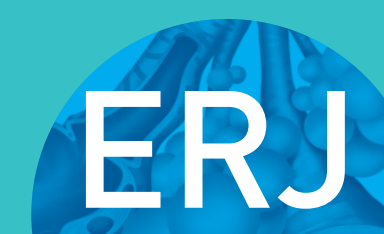

open research
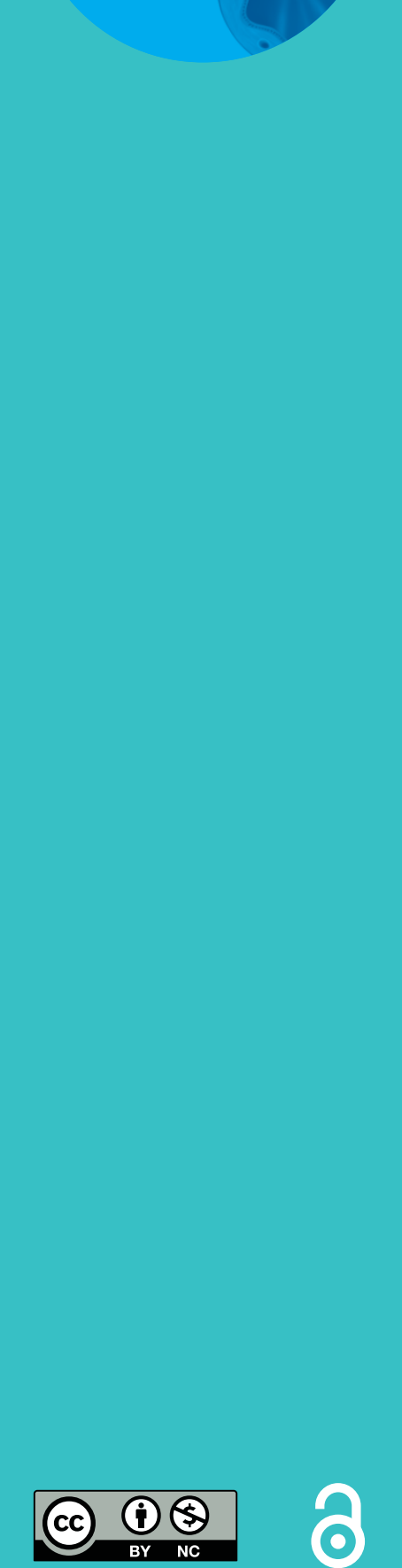

\section{Validity and reliability of the Multidimensional Dyspnoea Profile in older adults}

\author{
Eralda Hegendörfer (10 ${ }^{1,2}$, Alexander Doukhopelnikoff ${ }^{1}$ and \\ Jean-Marie Degryse ${ }^{1,2}$
}

Affiliations: ${ }^{1}$ Dept of Public Health and Primary Care, Katholieke Universiteit Leuven (KU Leuven), Belgium. ${ }^{2}$ Institute of Health and Society, Université Catholique de Louvain (UC Louvain), Belgium.

Correspondence: Eralda Hegendörfer, Academic Center for General Practice, KU Leuven, Dept of Public Health and Primary Care, Kapucijnenvoer 33 Blok J - Box 7001, 3000 Leuven, Belgium.

E-mail: eralda.turkeshidakuleuven.be

ABSTRACT Breathlessness is a common and distressing symptom in older adults and an independent predictor of adverse outcomes and yet its multidimensional assessment has not been validated in older adults. We apply and validate the Multidimensional Dyspnoea Profile (MDP) in a sample of adults 75 years and older in Belgium.

Breathlessness was rated with the MDP, the modified Borg Dyspnoea Scale (mBDS), the Short Physical Performance Battery (SPPB, a numerical rating scale for intensity and unpleasantness both before and after exertion), as well as with the Medical Research Council (MRC) Dyspnoea Scale. The Hospital Anxiety and Depression Scale (HADS) assessed the affective status. Factor structure was analysed with exploratory principal components analysis, internal consistency with Cronbach's alpha and concurrent validity with Spearman's correlation coefficients with other breathlessness scales, HADS and SPPB scores.

In 96 participants (mean age 85 years; $34 \%$ men) who rated breathlessness at both assessment points, exploratory principal components analysis identified two components: Immediate Perception (IP) and Emotional Reaction (ER), explaining most of the MDP item variance $(65.37 \%$ before and $71.32 \%$ after exertion). Internal consistency was moderate to high for MDP-IP (Cronbach's alpha $=0.86$ before and 0.89 after exertion) and MDP-ER (Cronbach's alpha $=0.89$ before and 0.91 after exertion). The correlation patterns of MDP-IP and MDP-ER with other tests confirmed concurrent validity.

The domain structure, reliability and concurrent validity of MDP for breathlessness before and after exertion were confirmed in a sample of adults 75 years and older, supporting its use and further research for the multidimensional profiling of breathlessness in older adults.

@ERSpublications

Domain structure, reliability and concurrent validity of the MDP were confirmed in a sample of adults aged $\geqslant 75$ years before and after exertion, supporting its use for the multidimensional assessment of breathlessness in this age group https://bit.ly/3emiNRW

Cite this article as: Hegendörfer E, Doukhopelnikoff A, Degryse J-M. Validity and reliability of the Multidimensional Dyspnoea Profile in older adults. ERJ Open Res 2021; 7: 00606-2020 [https:// doi.org/10.1183/23120541.00606-2020].

This article has supplementary material available from openres.ersjournals.com

Received: 24 Aug 2020 | Accepted: 28 Oct 2020

Copyright $\odot$ ERS 2021. This article is open access and distributed under the terms of the Creative Commons Attribution Non-Commercial Licence 4.0 


\section{Introduction}

Breathlessness is a common and distressing symptom in older adults, with around $30 \%$ of them reporting breathlessness during activities of daily living $[1,2]$. Breathlessness is not only a symptom of high-burden chronic diseases such as cardiorespiratory ones, but also a potential geriatric syndrome and independent marker of higher risk for adverse outcomes in older adults [3-7]. This has led to a call for its systematic and routine assessment $[8,9]$.

Despite this, breathlessness is a complex and multidimensional symptom including the sensory-perceptual experience (what breathing feels like), the affective distress (how distressing breathing feels) and the impact (how breathlessness affects functional ability or quality of life) [10]. However, breathlessness has so far been assessed mainly with unidimensional tools [1, 10]. Multidimensional tools have recently been developed and validated, such as the Multidimensional Dyspnoea Profile (MDP) [11, 12]. The MDP consists of 11 items that cover three domains: 1) unpleasantness/discomfort of the breathing sensation rated on a numerical scale from 0 to $10 ; 2$ ) five descriptors of the breathing sensation presented as a choice and the chosen descriptor is rated for its intensity on a numerical scale from 0 to $10 ; 3$ ) emotional responses to the breathing sensation (five) to be rated on their intensity on a numerical scale from 0 to 10 [12]. The MDP has been applied among patients in the emergency room, those with chronic obstructive pulmonary disease, with cardiorespiratory disease and hospitalised patients [13-18]. To our knowledge there are no studies so far that have applied and validated the MDP in older adults without focusing on a specific disease.

Older adults have a risk of under-reporting breathlessness because its subjective awareness and severity may be reduced due to the age-related altered sensory perception, and breathlessness may also be attributed to normal ageing $[2,9,19-23]$. That is why there is a need for specific validation studies for multidimensional breathlessness assessment tools in this growing age group.

This study aims to assess the psychometric qualities of the MDP before and after exertion in a sample of adults 75 years and older. We also investigate whether MDP scores differ between participants with different levels of physical performance and affective status.

\section{Methods and materials}

\section{Study design and population}

This was a cross-sectional study of Belgian adults 75 years and older who were clinically stable and living at their own homes or in nursing homes. Local nursing homes were invited to participate in the study. The institutions with a positive response provided a list of eligible residents. The inclusion criteria were adults 75 years and older who were clinically stable. Exclusion criteria were acute infection, unstable angina, myocardial infarction in the last month, illiteracy or a physical or cognitive disability that would not allow them to perform the assessment tests of the study. Study participants were randomly selected from the provided lists until 20 participants for an institution was reached. A convenience sample of participants living at home was also included, through personal contacts and invitations in two local assisted facilities. We aimed for a sample size of approximately 100 participants to fulfil sample size requirements for correlation and factor analysis studies [24]. After selection, each participant was informed about the research and asked to provide signed consent. The study was approved by the Ethics Committee of the Katholieke Universiteit Leuven, Leuven, Belgium (mp 18739).

\section{Data collection}

The assessment tests were performed in the living environment of the participants and they were randomly assigned to one of the three clinical research assistants, who received training to achieve a standardised assessment.

Demographic data were collected (sex, date of birth, type of residence) and height, weight, blood pressure, pulse and peripheral oxygen saturation $\left(S_{\mathrm{pO}_{2}}\right)$ were measured for each participant. The battery of tests was then carried out in the following order: the HADS [25, 26], the MRC Dyspnoea Scale [27], the mBDS [28], the Numerical Rating Scale for Intensity (NRS-I) and Unpleasantness (NRS-U) of breathlessness [10], and the MDP; then the SPPB [29] was performed followed by a second measurement of blood pressure, pulse and $S_{\mathrm{pO}_{2}}$ and a second assessment of breathlessness with the mBDS, NRS-I, NRS-U and MDP. For the first assessment the participants were asked about their breathlessness at the moment ("right now") and for the second assessment about their breathlessness at the end of exertion ("immediately after the last part of the SPPB").

The SPPB is a battery of physical performance tests to assess mobility and lower extremity function in older adults that has been widely used and is predictive of adverse outcomes such as mortality, disability and hospitalisation [29, 30]. It consists of 1) a standing balance test where the participant stands 
unassisted with feet together for at least $10 \mathrm{~s}$ in three positions (side by side, semi-tandem and tandem), 2) a walking speed test (measured time of walking $4 \mathrm{~m}$; the best of two attempts is used and the participant can use their walking aid), and 3) a chair stand test (standing up from a sitting position in a chair five times, without using the arms of the chair) [29]. Each test is assigned up to 4 points, leading to a possible total global performance score of 12, with higher scores indicating higher levels of physical functioning [29].

The MDP was used in the Dutch linguistically validated version available from the Mapi Research Trust (www.mapi-trust.org). Additional information about the other scales can be found in the supplementary material.

\section{Statistical analysis}

Baseline characteristics of the sample were analysed with descriptive statistics. The MDP was evaluated using the unpleasantness (MDP-A1) score, the Immediate Perception (MDP-IP) score (sum of the A1 score and the total sensory qualities' intensity score), and the Emotional Response (MDP-ER) score (A2 score) at both assessment points.

The factor structure of MDP was analysed with exploratory factor analysis using a varimax rotation. The Kaiser-Meyer-Olkin measure of sample adequacy and Bartlett's test of sphericity were used to test the suitability of our dataset for factor analysis. Internal consistency of each domain was analysed with Cronbach's alpha. Concurrent validity was assessed with Spearman's correlation coefficients (r) of MDP scores with NRS-I, NRS-U, MRC, mBDS, HADS, $S_{\mathrm{pO}_{2}}$ and SPPB scores and bootstrapping was used to calculate their $95 \%$ confidence intervals.

We used the lowest sex-specific quartile of the SPPB score to define lower physical performance and the highest quartile of anxiety (HADS-A) or depression (HADS-D) HADS scores for lower affective status. The difference in MDP scores between the two groups of physical performance and affective status was tested with the Mann-Whitney U-test. Statistical analysis was performed with SPSS 26.0 (IBM Corp., Armonk, NY, USA).

\section{Results}

A total of 100 participants were enrolled in the study between 12 April and 8 May 2018 (only four participants declined to perform the SPPB and have the second assessment). The mean age of the participants was 84.94 years (range 75-98 years), of whom $34 \%$ were male and $54 \%$ lived in nursing homes (table 1).

Before exertion, participants reported a median MDP-A1 score of 1 (interquartile range (IQR) 0-3); MDP-IP score of 2 (IQR 0-8) and MDP-ER score of 0 (IQR 0-4) (table 1). Most of the participants (58\%) did not choose any of the five sensory qualities of breathlessness provided by the MDP, while for the rest "breathing a lot" was the most frequently chosen sensory quality (14\%), followed by "mental effort or concentration" (13\%) (table 1). At the end of exertion, the most frequent sensory quality was "muscle effort or work" (29.2\%) followed by "breathing a lot" $(22.9 \%)$, while $34.4 \%$ still chose none of the five descriptors (table 1). The MDP scores at the end of exertion were higher than those before exertion, except for the MDP-ER score, which was the same (table 1). The majority of participants chose 0 in the scales for all five emotional descriptors at both assessments (before exertion: $84 \%$ for depressed, $76 \%$ for anxious, $78 \%$ for frustrated, $90 \%$ for angry and $82 \%$ for afraid; at end of exertion: $78 \%$ for depressed, $64 \%$ for anxious, $76 \%$ for frustrated, $82 \%$ for angry and $75 \%$ for afraid).

The exploratory principal components analysis (with varimax rotation) of the 11 items of the MDP identified two principal components that accounted for most of the item variance in the MDP scores (at both assessment points). A1 (Unpleasantness) and the five sensory qualities' intensities grouped together (Immediate Perception domain), while the five emotional response intensities grouped separately (Emotional Response domain). All factor loadings were $>0.60$ (table 2). The variance explained by the two factors was $65.37 \%$ before and $71.32 \%$ at the end of exertion. The Kaiser-Meyer-Olkin measure of sample adequacy $(>0.80)$ and Bartlett's test of sphericity $(\mathrm{p}<0.001)$ confirmed the suitability of our dataset for factor analysis (table 2).

Internal consistency was moderate to high for MDP-IP score (Cronbach's alpha $=0.86$ before and 0.89 at end of exertion) and MDP-ER score (Cronbach's alpha $=0.89$ before and 0.91 at end of exertion).

Estimates of concurrent validity of the MDP-A1, MDP-IP and MDP-ER scores with NRS-I, NRS-U, MRC, mBDS, HADS, $S_{\mathrm{pO}_{2}}$ and SPPB scores are presented in table 3. At both assessment points, MDP scores were significantly correlated with NRS-I, NRS-U, mBDS, MRC and HADS scores, but not with $S_{\mathrm{pO}_{2}}$ or SPPB score (except for MDP-IP) (table 3). Before exertion, MDP-IP had the highest correlations with NRS-U ( $r=0.69,95 \%$ CI 0.56-0.81), NRS-I and mBDS ( $r=0.61,95 \%$ CI 0.45-0.75), while for MDP-ER the 
Measurements

Participants n

Age years

Male

Height $\mathrm{m}$

Weight kg

BMI $\mathbf{k g} \cdot \mathrm{m}^{-2}$

Systolic BP $\mathrm{mmHg}$

Diastolic BP $\mathrm{mmHg}$

$\mathrm{S}_{\mathrm{pO}_{2}} \%$

$\mathrm{MDP}^{\#}$

MDP-A1 score

MDP-IP score

MDP-ER score

Sensory qualities

Other

Best match

Intensity

Muscle effort or work

Air hunger

Chest tightness

Mental effort or concentration

Breathing a lot

Sensory qualities' intensity total score

Emotional responses

Depressed

Anxious

Frustrated

Angry

Afraid

NRS $^{\#}$

Intensity

Unpleasantness

mBDS ${ }^{\#}$

MRC

0 (no breathlessness at all)

1 (short of breath only in strenuous exercise)

2 lshort of breath when hurrying on level/walking up a slight

hill)

3 lwalks slower than peers on level due to shortness of

breath/stops for breath after walking at own pacel

4 (stops for breath after walking $100 \mathrm{~m} / \mathrm{few}$ minutes on level ground)

5 (too breathless to leave the house or when un/dressing)

HADS

Total

Anxiety

Depression

SPPB
Before exertion

At end of exertion

00

$84.94 \pm 5.48$

34 (34)

$1.64 \pm 0.09$

$71.98 \pm 13.30$

$26.72 \pm 4.20$

$126.40 \pm 25.45$

$74.02 \pm 14.49$

$137.63 \pm 20.53$

$95.49 \pm 2.61$

$79.20 \pm 15.01$

$1(0-3)$

$2(0-8)$

$0(0-4)$

$2(0-3)$

$6(2-12)$

0 (0-4.75)

58 (58)

0

33 (34.4)

9 (9)

0 (0-0.75)

2 (2)

0

28 (29.2)

$1(0-4)$

2 (2.1)

$0(0-0)$

$0(0-0)$

$4(4.2)$

$0(0-0)$

$0(0-0)$

13 (13)

7 (7.3)

$0(0-1)$

$0(0-0)$

$22(22.9)$

$14(14)$

0 (0-3.75)

$0(0-6.75)$

$4(0-10)$

$0(0-0)$

$0(0-0)$

$0(0-0)$

$0(0-2)$

$0(0-0)$

$0(0-0)$

$0(0-0)$

$0(0-0)$

$0(0-0)$

$0(0-0)$

$0(0-4)$

$1(0-4)$

$0.5(0-3)$

$2(0-4)$

$2(0-4)$

2 (0.5-3)

$14(14)$

$23(23)$

19 (19)

8 (8)

18 (18)

$18(18)$

$13(7-16)$

6 (3-9)

$6(3.25-8)$

$5(3-8)$

Data are presented as mean \pm SD, $n(\%)$ or median (interquartile range), unless otherwise stated. BMI: body mass index; $B P$ : blood pressure; $S_{\mathrm{pO}_{2}}$ : peripheral oxygen saturation; MDP: Multidimensional Dyspnoea Profile; A1: Unpleasantness/Discomfort; IP: Immediate Perception; ER: Emotional Response; NRS: Numerical Rating Scale; mBDS: modified Borg Dyspnoea Scale; MRC: Medical Research Council Dyspnoea Scale; HADS: Hospital Anxiety and Depression Scale; SPPB: Short Physical Performance Battery. \#: number of participants with scores $>0$ as follows: MDP-A1 54 before and 69 after exertion; MDP-IP 34 before and 36 after; MDP-ER 65 before and 78 after; NRS-I (Intensity) 48 before and 66 after; NRS-U (Unpleasantness) 54 before and after; mBDS 63 before and 75 after. 


\begin{tabular}{|c|c|c|c|c|}
\hline \multirow[t]{3}{*}{ MDP items } & \multicolumn{4}{|c|}{ Rotated factor loadings } \\
\hline & \multicolumn{2}{|c|}{$\begin{array}{l}\text { Before exertion } \\
\text { ["At this moment"] }\end{array}$} & \multicolumn{2}{|c|}{$\begin{array}{l}\text { After exertion ("At the end } \\
\text { of last part of SPPB") }\end{array}$} \\
\hline & Factor 1 & Factor 2 & Factor 1 & Factor 2 \\
\hline Unpleasantness & 0.67 & 0.36 & 0.79 & 0.17 \\
\hline Muscle work or effort & 0.78 & 0.15 & 0.66 & 0.40 \\
\hline Air hunger & 0.84 & 0.09 & 0.88 & 0.23 \\
\hline Chest tightness/constriction & 0.65 & 0.40 & 0.78 & 0.40 \\
\hline Mental effort/concentration & 0.65 & 0.29 & 0.74 & 0.39 \\
\hline Breathing a lot & 0.75 & 0.33 & 0.69 & 0.26 \\
\hline Depressed & 0.25 & 0.83 & 0.32 & 0.78 \\
\hline Anxious & 0.35 & 0.71 & 0.35 & 0.74 \\
\hline Frustrated & 0.46 & 0.79 & 0.39 & 0.83 \\
\hline Angry & 0.11 & 0.81 & 0.18 & 0.85 \\
\hline Afraid & 0.22 & 0.77 & 0.28 & 0.82 \\
\hline KMO & 0.84 & & 0.89 & \\
\hline Bartlett's test of sphericity & $<0.001$ & & $<0.001$ & \\
\hline
\end{tabular}

MDP: Multidimensional Dyspnoea Profile; SPPB: Short Physical Performance Battery; KMO: KaiserMeyer-Olkin measure of sample adequacy.

highest correlations were with NRS-U ( $\mathrm{r}=0.55$, 95\% CI 0.38-0.69) and HADS-A ( $\mathrm{r}=0.52,95 \%$ CI 0.34-0.66) (table 3). At the end of exertion, MDP-IP had the highest significant correlation coefficients with NRS-I ( $\mathrm{r}=0.74,95 \%$ CI 0.62-0.83) and NRS-U ( $\mathrm{r}=0.70,95 \%$ CI 0.56-0.81), while for MDP-ER the highest correlations were with NRS-U ( $\mathrm{r}=0.49$, 95\% CI 0.32-0.64) and HADS-A ( $\mathrm{r}=0.48$; 95\% CI $0.32-0.62$ ) (table 3). At both assessment points, MDP-IP had a statistically significant negative correlation with the SPPB score ( $r=-0.21$ before and -0.27 at end of exertion) (table 3 ).

There were no statistically significant differences for MDP-A1, MDP-ER and MDP-IP scores between physical performance groups (those in the lowest sex-specific quartile of the SPPB score versus the rest of the sample) (figure 1). Before exertion, participants in the highest quartile for HADS-A and HADS-D had significantly higher MDP-A1, MDP-IP and MDP-ER scores compared to the rest of the sample (figure 1). At the end of exertion, those in the highest quartile of HADS-A had significantly higher MDP-IP and MDP-ER scores, while those in the highest quartile of HADS-D had only a significantly higher MDP-ER score (figure 1).

\section{TABLE 3 Correlations of MDP scores with other breathlessness measures, HADS, $\mathrm{S}_{\mathrm{pO}_{2}}$ and SPPB before and at the end of} exertion

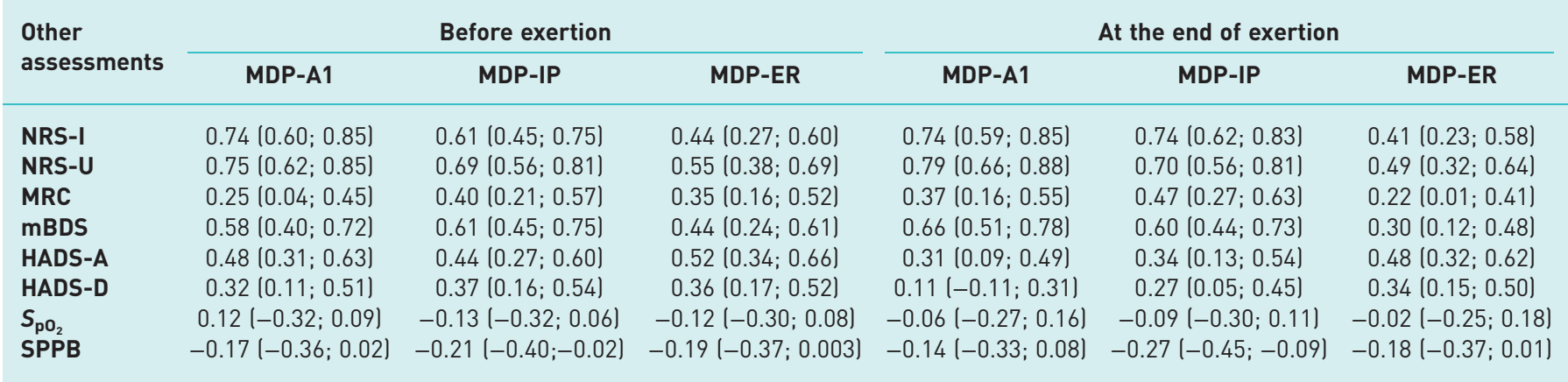

Data are presented as Spearman correlation coefficient (95\% confidence interval). MDP: Multidimensional Dyspnoea Profile; A1: Unpleasantness; IP: Immediate Perception; ER: Emotional Response; NRS: Numerical Rating Scale; I: Intensity; U: Unpleasantness; MRC: Medical Research Council Dyspnoea Scale; mBDS: modified Borg Dyspnoea Scale; HADS: Hospital Anxiety and Depression Scale; A: Anxiety; D: Depression; $\mathrm{S}_{\mathrm{pO}_{2}}$ : peripheral oxygen saturation; SPPB: Short Physical Performance Battery. 

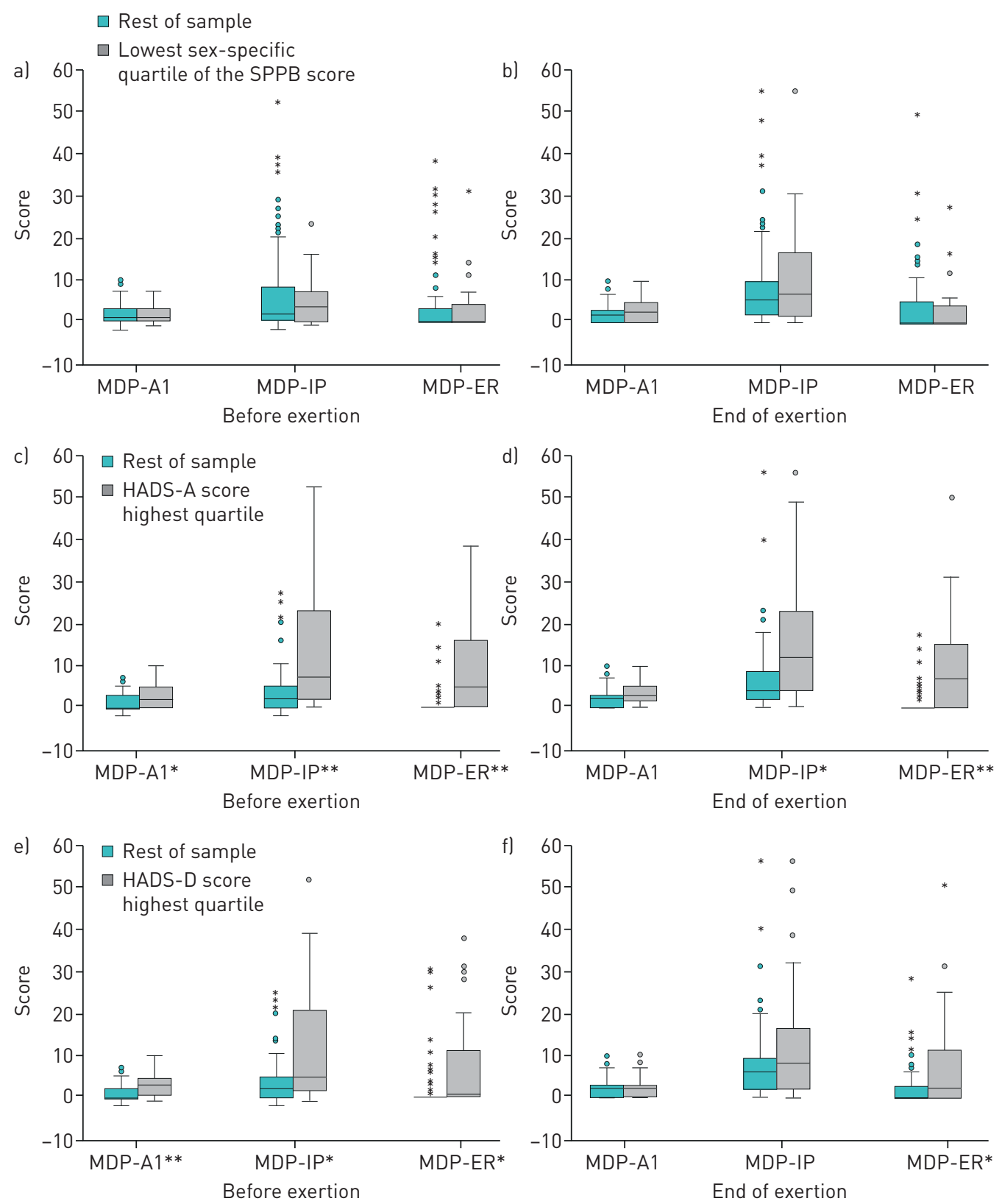

FIGURE 1 MDP scores before and at the end of exertion for different performance groups of SPPB, HADS-A and HADS-D. The boxes represent the interquartile range of the scores. The black horizontal line in each box represents the median score and the whiskers the minimum and maximum scores. Outliers are represented by circles and extreme outliers by asterisks. MDP: Multidimensional Dyspnoea Profile; A1: Unpleasantness; IP: Immediate Perception; ER: Emotional Response; HADS: Hospital Anxiety and Depression Scale; A: Anxiety: D: Depression; SPPB: Short Physical Performance Battery. Statistical significance of the difference tested with Mann-Whitney U-test. *: $p<0.05 ;{ }^{* *}$ : $p<0.001$.

\section{Discussion}

In our sample of adults 75 years and older who were clinically stable and living either at their own homes or in a nursing home, the MDP showed validity for the multidimensional assessment of breathlessness based on factor structure, reliability and concurrent validity both before and after exertion. MDP scores were statistically different for different affective status groups of participants, but not for different physical performance groups.

To our knowledge, this study is the first to implement and assess the validity of the MDP and provide a multidimensional profile of breathlessness before and after exertion in a sample of older adults 75 years and older without focusing on a selected disease. The factor analysis showed a two-factor structure of 
MDP as in the original MDP study and other MDP validation studies, with the 11 items grouped under IP and ER [13, 16, 18]. This two-domain structure was valid at both assessment times. The internal consistency was also moderate to high and similar to previous MDP studies $[13,16,18]$.

At both assessments, the MDP-IP and MDP-ER had different patterns of correlations with the other tests. The MDP-IP correlated well with other sensory-perceptual domain measures of breathlessness such as NRS-I, NRS-U and mBDS, but much less with the MRC, which measures another dimension of breathlessness (impact in functional performance). Measures of breathlessness that assess the sensory-perceptual dimension (NRS-I, NRS-U, mBDS) had higher correlations with MDP-IP than with MDP-ER at both assessment points. HADS-A and HADS-D had higher correlations with MDP-ER than MDP-IP in both assessment points, although in the weak-moderate range $(r=0.34-0.52)$. These findings are comparable with those of the original MDP validation study [13], as well as MDP studies in other settings $[15,16,18]$.

Even though $44 \%$ of our study participants rated their breathlessness with the MRC $\geqslant 3$ (moderate-severe), focusing on breathlessness at this moment (before exertion) and at the end of the exertion, the majority of participants had NRS-I, mBDS and MDP-A1 scores <4, which has been proposed as a cut-off for moderate-severe breathlessness [17]. This discrepancy may be related not only to different tools capturing different dimensions of breathlessness (sensory-perceptual versus functional impact), but also because the present (at rest) and exertion-induced breathlessness are different constructs from breathlessness during activities of daily living [31, 32].

\section{Emotional response to breathlessness}

The majority of participants in our study (66\% before and $62.5 \%$ at end of exertion) rated the intensity for all five emotional descriptors as zero. As MDP-A1 scores were low both before and at the end of exertion, participants may have experienced a level of breathlessness intensity that was not strong enough to cause a considerable emotional response towards it, especially in the familiar and supervised environment where the testing took place [16]. The affective/emotional response to breathlessness may vary independently from its intensity and sensation and is determined by the individual affective style (emotional response to unpleasant stimuli) [33,34]. The MDP aims to capture this affective style [13], yet the affective style of older adults differs from younger ones [20,35]. Positive emotions may reduce the affective response to breathlessness [36] and older adults are overall more optimistic and have a more positive view of their health than would be expected based on their morbidity and functional status $[20,35]$. Future research needs to explore the possible age-related alteration of the affective response to breathlessness in older adults [20].

At both assessment points, MDP-IP and MDP-ER scores were not significantly different between participants with different levels of physical performance status (based on SPPB score), but they were different between groups of affective status (based on HADS-A and HADS-D scores). These findings suggest that in our sample of older adults the multidimensional profiling of breathlessness was influenced more by the affective status of the participants than their physical performance.

\section{Sensory qualities of breathlessness}

In our study, before exertion the majority of participants (58\%) could not identify with any of the five descriptors provided in the MDP. Yet, at the end of exertion, the majority of participants identified with one of the provided descriptors, mostly with "muscle effort or work" (29.2\%) and "breathing a lot" (22.9\%). These are common sensory qualities of the breathlessness induced through exertion, as was the case in our study [10]. For most participants in previous research, it has been difficult to provide an exact description of the breathing discomfort, which is why providing a list of descriptors to choose from has been helpful [11]. The language used to describe sensory qualities of breathlessness has been studied widely, but it has not been specifically studied in older adults who may provide a different set of sensory qualities, especially as breathlessness in older adults is more common in a multiple comorbidity setting, multifactorial and under the influence of age-related blunted perception [2, 3, 19, 20, 22, 35]. Additionally, the linguistic separation between intensity of breathlessness and its unpleasantness is difficult, so assessing the true difference between these two dimensions may be difficult $[13,33,37,38]$. Our study participants found this difficult as well, and even the example of the noise and music was not very helpful for them. This remains an aspect of the MDP that could be researched for further refinement.

\section{Multidimensional profiling of breathlessness in older adults}

There is a growing consensus that breathlessness needs to be assessed taking into account all its recognised dimensions: sensory/physical, affective and impact on daily life [10,37]. This would provide a better understanding of its causes and mechanisms, help with the diagnosis as certain sensory qualities are more 
related to a certain diagnosis, and with management decisions, as different available interventions address the sensory and affective dimensions of breathlessness [10, 11, 19, 37].

Previous studies with multidimensional tools for assessment of breathlessness such as MDP have not focused on older adults, but on participants with breathlessness related to a specific disease. Breathlessness in older adults is mostly present in a multimorbidity setting, is multifactorial, may be influenced by the age-related sarcopenia, blunted perception and potentially altered affective reaction, and has a tendency to be attributed to normal ageing $[2-4,7,19,20,22,23,35]$. These specific features of breathlessness in older adults and its potential as a predictor of adverse outcomes independently from cardiorespiratory diseases call for more focused research of its multidimensional assessment. MDP maps the sensory-perceptual and affective dimensions of breathlessness and seems to be a valid tool for the multidimensional assessment of breathlessness in older adults. Further research needs to test its validity in larger samples of older adults and consider possible adjustments for its use in this age group based on a feasibility analysis [39].

\section{Strengths and limitations}

This study provides for the first time, to the best of our knowledge, data on the performance of the MDP in a sample of older adults without any selection for a specific disease. The standardised comprehensive battery of tests including different breathlessness assessment tools allowed the investigation of concurrent validity of the MDP, but also increased the risk of survey fatigue.

The use of a convenience sample and exclusion criteria are limitations of this study. Despite this, the sample was adequate for running factor analysis and the MDP scores showed consistency before and after exertion and between different levels of physical and affective status. We also lacked information on the morbidity status of our participants, which could have provided a more comprehensive profile of their health status. While the SPPB is a recognised and valid tool to assess the physical performance of older adults, it may not have been enough exertion to cause more than a mild level of breathlessness and this may have influenced the findings.

\section{Conclusions}

This study confirmed the domain structure, reliability and concurrent validity of the MDP for breathlessness before and after a short battery of physical performance tests in a sample of adults 75 years and older in Belgium. These findings support the use of and further research into the MDP for the multidimensional assessment and profiling of breathlessness in older adults.

Acknowledgements: The authors would like to acknowledge the valuable contribution of Bram Jackers and Thomas Pacolet (KU Leuven, Belgium) to the application of the study's protocol and the data collection.

Conflict of interest: None declared.

Support statement: The data analysis and writing of this research paper was made possible through funds from the 'Funds for Scientific Research Flanders (Fonds voor Wetenschappelijk Onderzoek Vlaanderen)', grant number G037618N. Funding information for this article has been deposited with the Crossref Funder Registry.

\section{References}

1 van Mourik Y, Rutten FH, Moons KG, et al. Prevalence and underlying causes of dyspnoea in older people: a systematic review. Age Ageing 2014; 43: 319-326.

2 Mahler DA, Fierro-Carrion G, Baird JC. Evaluation of dyspnea in the elderly. Clin Geriatr Med; 19 : 19-33.

3 Miner B, Tinetti ME, Van Ness PH, et al. Dyspnea in community-dwelling older persons: a multifactorial geriatric health condition. J Am Geriatr Soc 2016; 64: 2042-2050.

4 Hegendörfer E, Vaes B, Matheï C, et al. Correlates of dyspnoea and its association with adverse outcomes in a cohort of adults aged 80 and over. Age Ageing 2017; 46: 994-1000.

5 Pesola GR, Ahsan H. Dyspnea as an independent predictor of mortality. Clin Respir J 2016; 10: $142-152$.

6 Vaz Fragoso CA, Araujo K, Leo-Summers L, et al. Lower extremity proximal muscle function and dyspnea in older persons. J Am Geriatr Soc 2015; 63: 1628-1633.

7 Ramalho SHR, Santos M, Claggett B, et al. Association of undifferentiated dyspnea in late life with cardiovascular and noncardiovascular dysfunction: a cross-sectional analysis from the ARIC study. JAMA Netw Open 2019; 2 : e195321.

8 Banzett RB, O'Donnell CR. Should we measure dyspnoea in everyone? Eur Respir J 2014; 43: 1547-1550.

9 Bousquet J, Dinh-Xuan AT, Similowski T, et al. Should we use gait speed in COPD, FEV1 in frailty and dyspnoea in both? Eur Respir J 2016; 48: 315-319.

10 Parshall MB, Schwartzstein RM, Adams L, et al. An official American Thoracic Society statement: update on the mechanisms, assessment, and management of dyspnea. Am J Respir Crit Care Med 2012; 185: 435-452.

11 Banzett RB, O'Donnell CR, Guilfoyle TE, et al. Multidimensional Dyspnea Profile: an instrument for clinical and laboratory research. Eur Respir J 2015; 45: 1681-1691.

12 Banzett RB, Moosavi SH. Measuring dyspnoea: new multidimensional instruments to match our 21 st century understanding. Eur Respir J 2017; 49: 1602473.

13 Meek PM, Banzett R, Parsall MB, et al. Reliability and validity of the Multidimensional Dyspnea Profile. Chest 2012; 141: 1546-1553. 
14 Parshall MB, Meek PM, Sklar D, et al. Test-retest reliability of Multidimensional Dyspnea Profile recall ratings in the emergency department: a prospective, longitudinal study. BMC Emerg Med 2012; 12: 6.

15 Morélot-Panzini C, Gilet H, Aguilaniu B, et al. Real-life assessment of the multidimensional nature of dyspnoea in COPD outpatients. Eur Respir J 2016; 47: 1668-1679.

16 Williams MT, John D, Frith P. Comparison of the Dyspnoea-12 and Multidimensional Dyspnoea Profile in people with COPD. Eur Respir J 2017; 49: 1600773.

17 Stevens JP, Sheridan AR, Bernstein HB, et al. A multidimensional profile of dyspnea in hospitalized patients. Chest 2019; 156: 507-517.

18 Ekström M, Bornefalk H, Sköld M, et al. Validation of the Swedish Multidimensional Dyspnea Profile (MDP) in outpatients with cardiorespiratory disease. BMJ Open Respir Res 2019; 6: e000381.

19 Battaglia S, Sandrini MC, Catalano F, et al. Effects of aging on sensation of dyspnea and health-related quality of life in elderly asthmatics. Aging Clin Exp Res 2005; 17: 287-292.

20 Petersen S, von Leupoldt A, Van den Bergh O. Geriatric dyspnea: doing worse, feeling better. Ageing Res Rev 2014; 15: 94-99.

21 Riegel B, Dickson VV, Cameron J, et al. Symptom recognition in elders with heart failure. J Nurs Scholarsh 2010; 42: $92-100$.

22 Berry CE, Han MK, Thompson B, et al. Older adults with chronic lung disease report less limitation compared with younger adults with similar lung function impairment. Annals Am Thorac Soc 2015; 12: 21-26.

23 Guenette JA, Jensen D. Aging and sex differences. In: Mahler DA, O’Donnell DE, eds. Dyspnea: Mechanisms, Measurement, and Management. 3rd Edn. Boca Raton, CRC Press, 2014; pp. 25-37.

24 de Vet HCW, Terwee CB, Mokkink LB, et al. Measurement in Medicine: A Practical Guide. Cambridge, Cambridge University Press, 2011.

25 Zigmond AS, Snaith RP. The hospital anxiety and depression scale. Acta Psychiatr Scand 1983; 67: 361-370.

26 Spinhoven P, Ormel J, Sloekers PP, et al. A validation study of the Hospital Anxiety and Depression Scale (HADS) in different groups of Dutch subjects. Psychol Med 1997; 27: 363-370.

27 Bestall JC, Paul EA, Garrod R, et al. Usefulness of the Medical Research Council (MRC) dyspnoea scale as a measure of disability in patients with chronic obstructive pulmonary disease. Thorax 1999; 54: 581-586.

28 Wilson RC, Jones PW. A comparison of the visual analogue scale and modified Borg scale for the measurement of dyspnoea during exercise. Clin Sci 1989; 76: 277-282.

29 Guralnik JM, Simonsick EM, Ferrucci L, et al. A short physical performance battery assessing lower extremity function: association with self-reported disability and prediction of mortality and nursing home admission. J Gerontol 1994; 49: M85-M94.

30 Guralnik JM, Ferrucci L, Simonsick EM, et al. Lower-extremity function in persons over the age of 70 years as a predictor of subsequent disability. N Engl J Med 1995; 332: 556-561.

31 Cullen DL, Rodak B. Clinical utility of measures of breathlessness. Respir Care 2002; 47: 986-993.

32 Gift AG, Narsavage G. Validity of the numeric rating scale as a measure of dyspnea. Am J Crit Care 1998; 7: 200-204.

33 Banzett RB, Pedersen SH, Schwartzstein RM, et al. The affective dimension of laboratory dyspnea: air hunger is more unpleasant than work/effort. Am J Respir Crit Care Med 2008; 177: 1384-1390.

34 O'Donnell CR, Schwartzstein RM, Lansing RW, et al. Dyspnea affective response: comparing COPD patients with healthy volunteers and laboratory model with activities of daily living. BMC Pulm Med 2013; 13: 27.

35 Parulekar AD, Martinez C, Tsai C-L, et al. Examining the effects of age on health outcomes of chronic obstructive pulmonary disease: results from the Genetic Epidemiology of Chronic Obstructive Pulmonary Disease Study and Evaluation of Chronic Obstructive Pulmonary Disease Longitudinally to Identify Predictive Surrogate Endpoints cohorts. J Am Med Dir Assoc 2017; 18: 1063-1068.

36 von Leupoldt A, Mertz C, Kegat S, et al. The impact of emotions on the sensory and affective dimension of perceived dyspnea. Psychophysiology 2006; 43: 382-386.

37 Lansing RW, Gracely RH, Banzett RB. The multiple dimensions of dyspnea: review and hypotheses. Respir Physiol Neurobiol 2009; 167: 53-60.

38 Ekström M, Williams M, Johnson MJ, et al. Agreement between breathlessness severity and unpleasantness in people with chronic breathlessness: a longitudinal clinical study. J Pain Symptom Manage 2019; 57: 715-723.

39 Ekström MP, Bornefalk H, Sköld CM, et al. Minimal clinically important differences and feasibility of Dyspnea-12 and the Multidimensional Dyspnea Profile in cardiorespiratory disease. J Pain Symptom Manage 2020; 60: 968-975. 